\title{
Global Science for city policy
}

\author{
It is time for a global reform of science advice to cities \\ By Michele Acuto ${ }^{1,2}$ \\ ${ }^{1}$ Melbourne School of Design, University of Melbourne, \\ ${ }^{2}$ UCL STEaPP, University College London.
}

Research and data are increasingly at the heart of how we conceive of urban governance. Urban control rooms and city dashboards championed by cities like Chicago, Sao Paulo and London have been promising real-time snapshots and tracking over time of urban systems, via geo-located mobility datasets, social media inputs, environmental sensors, and other tools (1). At the international level, the importance of urban research and data has been enshrined in major United Nations (UN) processes from the UN New Urban Agenda, the Sendai Framework on disaster risk reduction, the Sustainable Development Goals (SDGs), to the World Data Forum (2). Yet overall, the global state of data-informed urban governance remains underdeveloped, often promising, as with the dashboards, more than it actually delivers. It is time for a step change. A truly global reform of scientific advice to cities needs to take place on multiple interconnected fronts, linking a UN action plan on science and the future of cities, a 'good advice' commitment by the private sector, and formalized partnerships for urban science at the local level. This scientifically-informed urban reform, ripe for discussion at the upcoming UN World Urban Forum in February, can be uniquely bold in recognizing the potential of municipal action on global challenges. Despite being considered the 'lowest' level of governance, cities have developed a track record of global action on key matters like climate, disasters, and health, often surpassing, in speed, commitments, and global coverage, that of nations.

Scientific assessments have long been intertwined with urban management. Civil engineering has roots in $19^{\text {th }}$ century public health mapping and mobility data collection as 'sanitary science' developed in response to cholera outbreaks in the largest hubs of the industrial revolution. Yet today cities are asking for, sharing, and generating data like never before. Open data portals are well established, with London making more than 600 datasets available, Chicago more than

Melbourne School of Design, University of Melbourne, Australia.Email:m.acuto@unimelb.edu.au
1,000 , and Seoul in excess of 4,500. More cities are undertaking more performance reviews and data snapshots. Melbourne, with five such reports available in 2010, has 26 today, in line with trends in Singapore, New York or Paris. Cities are seeking to capture the value of data production to instill innovation at the heart of urban policy. The Boston mayor's office of New Urban Mechanics, formed in 2010, has generated internationally visible data-driven innovations like StreetBump, using GPS smartphone accelerometers to report road damages.

Opportunities for cross-national connections of urban information have grown via city networks like $\mathrm{C} 40$ Cities (from 60 networks in 1990 to over 200 active today) with most of them now regularly engaging in evidence-based reporting. (3) Information sharing is becoming central to this internationalization of urban governance. For instance, over 7,400 cities are signed up to the Global Covenant of Mayors to implement the 2016 Paris Agreement on climate change, vowing proactive, well-informed action to tackle and monitor global warming at the urban level.

Yet data availability does not immediately translate into better informed urban management, nor fairer, greener and more prosperous cities. For instance, some of the most useful transport data are often held by ride sharing companies like Uber and Lyft, especially in the Global South, with substantial legal and commercial barriers to use for the public good (4). Traditional census approaches, or uncertain and costly data generation and analysis methods, force many cities to "plan in the dark" as critical matters like infrastructure provision and extreme poverty are routinely undercounted. (5).

\section{RETHINKING ADVICE?}

Several critical problems prevent solid research-based advice from informing city governance. There is no common 'urban science': realms as diverse as computer science and literature rarely work together in applied programs addressing urban challenges. Much better integration of different disciplines is paramount to success. Qualitative assessments based on ethnographic accounts are often perceived as of marginal policy importance versus quantitative big data depictions, despite those potentially being equally plagued with limitations. Urban science needs to be fit for (policy) purpose, and urban policymakers need to appreciate the value of multiple forms of research(6). But impact-savvy scholarship is still too rare and at times frowned upon in academia.

The disparity is also evident in the focus of science and capacity for data analytics. There is a 'metrocentric' bias (7) between larger cities like London and Seoul are growing their information capabilities and datadriven innovation, smaller cities in the developing world and on the margins of global hubs tend to lag behind even though they actually represent the bulk of urbanization. If we have tools (e.g., to monitor air pollution or geo-located street safety), we need a global effort to not limit them to the centers of the world's economy. A UN initiative, and buy in of national governments, is critical to step beyond the data power of the global cities and the market ebbs of the private sector.

Much of the most recognized, connected and internationally effective urban analysis does not come today, at least prima facie, from scholarly institutions, further skewing the drivers of urban scientific advice and complicating problems of impartiality and accountability in impact-oriented research. For instance, it is global insurance giant Swiss RE, not the UN, that holds some of the most comprehensive detail of urban risk from natural disasters. (8) Philanthropy has been one of the most fundamental forces in the informed cities paradigm, e.g., Deutsche Bank support for the LSE Urban Age program, or the Arnold Foundation peer network of urban 'chief data officers' in the US. Global engineering consultancy Arup has been behind assessments produced by $\mathrm{C} 40$ Cities and Rockefeller 100 Resilient Cities, and JP Morgan or Jones Lang Lasalle have been steering of the 'global city' discourse.

Without effective reform in the UN system, and consequent buy in by national governments, there is little hope for truly global action that goes beyond private interests and 
networked efforts by cities which are necessarily selective in the way they connect across borders. UN-Habitat, the UN's main 'urban' agency, is plagued by budgetary concerns while other better-equipped UN agencies like the World Health Organization (WHO) cannot shoulder a multi-sectorial cities effort while also representing specific agendas like that in WHO's Shanghai 2016 consensus for Healthy Cities.

Many diplomats and national interests in an international setting are resistant to reforms on urban science advice. Despite some initial momentum, the New Urban Agenda and the UN General Assembly have shelved both the idea of an intergovernmental panel on urban change akin to climate's IPCC, and the idea of a new inter-agency body, 'UNUrban', to coordinate multilateral efforts on cities beyond specific agencies' interests. In the Secretary General's UN reform agenda both proposals remain on the table, but face opposition.

Initiatives that combine local knowledge and technological advances, and coalesce private sector, local government and civil society actors offer perhaps the best promises. For example, the 'Know Your City' program led by Slum Dwellers International in collaboration with the Santa Fe Institute, Cities Alliance and the Gates Foundation, has produced perhaps the largest census, GIS and infrastructure data for over 7,712 slums and 224 cities globally. (9) Such efforts, though promising, still struggle for more than opportunist action in a crowded multilateral system.

\section{SCIENCE IN CITIES: A GLOBAL PLAN}

A reform of scientific advice to cities needs to happen jointly at local, national and multilateral levels. This entails a truly globally-oriented plan to encourage topical and geographical rebalancing of urban science, more evidence-based policy centered on scholarly analysis, and formalized science-policy mechanisms. This needs to be rolled out on four key fronts.

Local partnerships. Local collaborations should feed science directly into city executives. Although still a rarity, and without clear examples of success, the idea of a Chief Scientific Advisor (CSA) has had some unjustly limited foray into local government. University-city partnerships are also critical. In South Africa the Gauteng City-Region Observatory (GCRO) was established in 2008 as a partnership between the Universities of Johannesburg and Witwatersrand, and the Gauteng Provincial Government, and has de- veloped one of the best platforms to encourage scientifically-driven urban management but also local capacity building. Urban observatories and chief scientists are no long unaffordable or a luxury worth dispensing of in urban governance.

Private commitments. A concerted effort by the private and philanthropic sector toward provision of balanced and unbiased advice to cities is overdue. Private funding shaping information in cities today highlights challenges of 'philantrocapitalism' (10), criticized for the inevitable earmarking of private agendas and skewing of public priorities. Evidence-based policy of the scientific kind needs to rest on some degree of replicability and accountability of the data produced and its producers, which many global private actors shy away from. A code of practice akin to the Good Humanitarian Donorship program in the disaster relief sector, which has since 2003 fostered discussion against earmarking when it comes to development aid, could be a start.

National processes. More serious national foresight and monitoring efforts by central governments are imperative. Empowering science advice, and understanding it is increasingly a global business, is essential for all level of policymaking - and cities should not be forgotten. (11) The emergence of ' national urban policies' ( 35 and counting) is encouraging, but the 'cities' agenda is often so transversal to infrastructure, economics, culture, foreign policy, and other concerns that cities are too often everyone's business and thus no one's business, lacking clear recognition or a ministry. The U.S. President's Council of Advisors on Science and Technology called in 2016 for a cross-agency coordination system on cities. One such model is Chile's National Council for Urban Development contributing scientifically-based expertise to the country's national urban policy. At the central government level, assessment exercises to understand the future of cities, as with the long-lived futures expertise in Singapore's national urban planning, have demonstrated that states can support their urban environments effectively in the creation of better data-driven policy. National and local processes can feed off each other, rather than remaining parallel tracks. In the UK, Newcastle City Futures was established in 2014 by Newcastle University as a collaborative foresight platform building on the UK Government Office for Science's Foresight Future of Cities program. More of these are needed and can be built with support from regional bodies (e.g. the EU and ASEAN) as much as multilateral funders.
Multilateral reform. The multilateral world is still failing urban science and cities. A UN-Urban and an 'urban change' scientific panel would articulate a 'cities contribution' to UN efforts across sectors, mobilizing the urban science community that stood behind its establishment of an "Urban SDG" (SDG11) and the Habitat III process (15). Strengthening UN-Habitat, rather than betting on UNUrban, could also play this role. Yet this would require a stronger and formalized partnership with academia. Here UNoriented action is key to shift the he scale of urban science. Despite numerous "city rankings" and case studies, and some mounting interest in comparative research, there is too little truly 'global' urban science capable of conveying shared patterns, trends and needs (12).

Starting from the UN level, in whichever of these formats, could inspire more formal multilevel policy efforts that can nudge national politics more explicitly towards cities, encouraging a cross-cutting reform of the ways information is collected and deployed in city politics. This could for instance start from tracking at city level progress on the $11^{\text {th }}$ SDG (on sustainable cities), as already tested in the United States by the Sustainable Development Solutions Network, or by mirroring the efforts of the Global Burden of Disease program, to track urbanization on key SDG areas like health, gender and clean energy.

Cities are stepping up to global challenges and their leadership is more and more vital to addressing effectively both local as much as international concerns. Mobilising effectively as much as thorough urban science advice for city leadership is no academic qualm. Price for failure on this front is high: cities are increasingly at the forefront of inequality, disasters and economic downturns. Informing them appropriately and accountably is not just a moral and scientific, but also a political, duty.

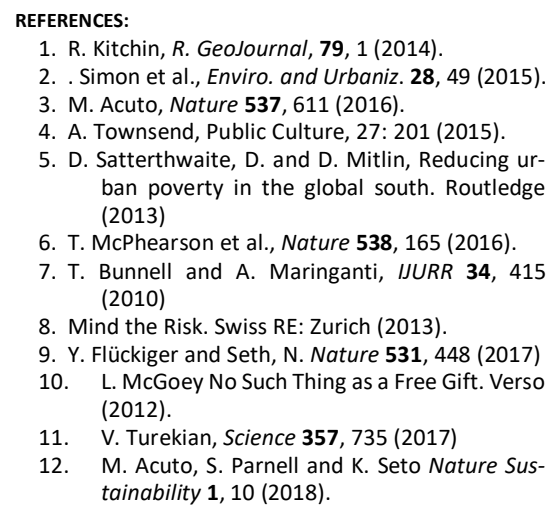

